\title{
A proposito de un caso: Linfoma de Natural killer post tratamientode Leishmaniasis
}

DOI: $10.46981 /$ sfjhv2n2-008

Received in: April 1st, 2021

Accepted in: May 31th, 2021

\author{
Jhonatan Nieto Centeno \\ Medicine - Universidad de Pamplona \\ Bucaramanga Emergency Clinic. \\ Cra 27a \# 48-62 Apartment 604, Palmas de Mardel Complex, Barrio Soto Mayor, Bucaramanga \\ Santander. \\ E-mail: Jhntncenteno@gmail.com \\ Gustavo Adolfo Comas Piñerez \\ Medicine - Universidad de Pamplona \\ Regional Hospital of Magdalena Medio. \\ E-mail: gcomasp92@gmail.com

\section{Quintero M} \\ Hematólogo \\ E.S.E Hospital Universitario Erasmo Meoz
}

\section{INTRODUCCIÓN:}

Linfoma de células T/NK es un linfoma noHodking agresivo y muy poco común, el cual se localizan principalmente en la regióncentro facial afectando principalmente las fosas nasales y los senos maxilofaciales con un amplio pleomorfismo, aunque también pueden afectar tórax y extremidades generando frecuente necrosis y angioinvasión. ${ }^{1}$ Su comportamiento es agresivo, su diagnóstico es difícil y con mala respuesta al tratamiento.

\section{OBJETIVO GENERAL:}

Dar a conocer una patología poco frecuente en nuestra región, su presentación clínica y naturaleza de la misma, tras un falso tratamiento para una enfermedad no relacionada

\section{OBJETIVO ESPECÍFICO:}

1. Demostrar el falso diagnóstico de leishmiasis posterior a culminación de tratamiento y otras causas a dichocuadro clínico.

2. Exponer mediante imágenes laextensión de las lesiones compatiblescon lesiones provocada por patología. 


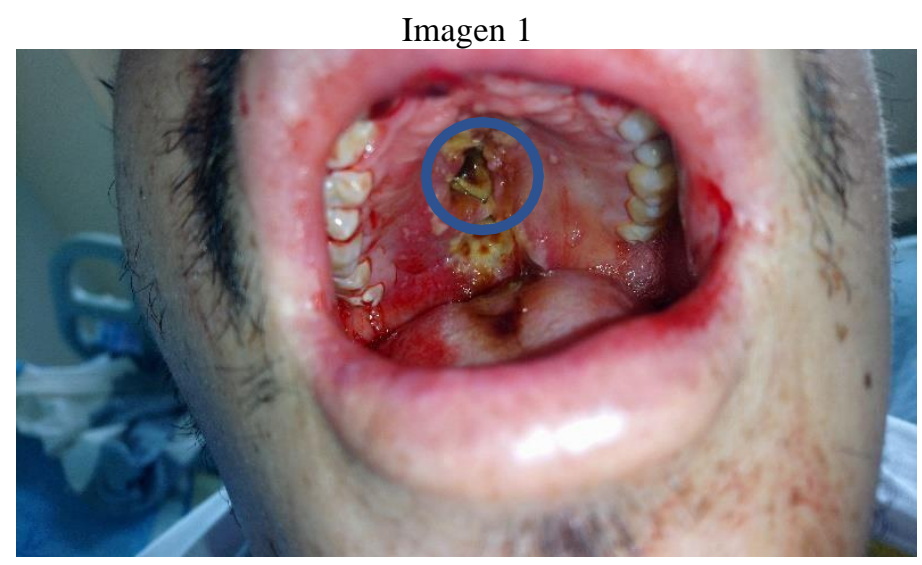

\section{RESUMEN DE CASO CLÍNICO:}

En nuestro caso clínico se trata de un Pacientemasculino de 27 años multiconsultante en los servicios de urgencias procedente de un Municipio local del departamento quien ingreso por lesión en paladar duro a la cual se le realiza múltiples biopsias en el 2016 donde reporta como diagnostico leishmaniasis, se indica tratamiento médico y posterior a ello lalesión permanece, aumenta su tamaño / diámetro presentando signos de infección (imagen 1) y expandiéndose a demás tejidos adyacente llegando a provocar cefaleas frontales, síndromes convulsivos, broncoaspiración y pansinusitis.

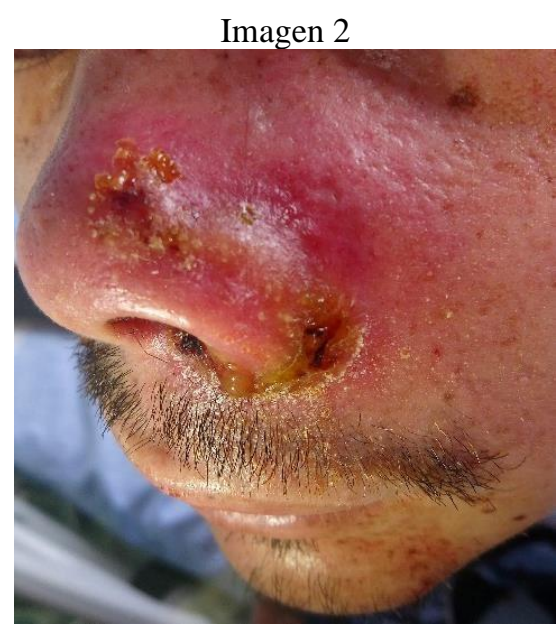

Al ingreso a la institución HUEM en el 2018 seevidencia aumento de lesión en región facial / nasal como se evidencia en imagen 2, se realizan nuevos estudios como IgG e IgM paraleishmaniasis resultado negativo lo cual nos indica que el paciente nunca presento dicha patología, se realizar otros estudios de extensión descartando otro tipo de lesiones mococutaneas como mucormicosis. Se indicola realización de TAC donde se evidencia discontinuidad del paladar duro con destrucción del mismo lo que se asocia a episodios de broncoaspiración, compromiso de la lámina cribosa por lo que realizo 
episodios convulsivos y lesión ocupante de espacio en senos paranasales por lo que cursaba con pansinusitis (imagen 3).

Se introdujo un hisopo para evidencia la profundidad de la lesión en paladar duro la cual se puede ver con signos de infecciónlocal, sangrado y necrosis como se evidencia en la primera imagen, el hisopo que mide se introdujo hasta tener $7 \mathrm{~cm}$ de profundidad, Los signos de infección sobre el paladar duro se dio manejo como osteomielitis.

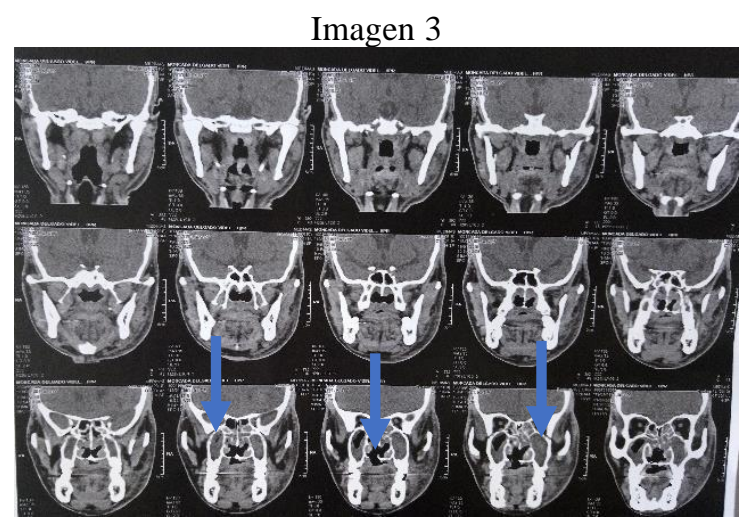

Se realizan nuevas biopsias donde el diagnóstico es: tumor maligno pobremente diferenciado que requirió estudios complementarios con marcadores de inmunohistoquimica arrojando desorden linfoproliferativo $\mathrm{T}$ compatible con linfoma decélulas T/NK, debido a nivel de complejidad serealiza remisión del paciente a clínica de alto nivel de complejidad para valoración por especialidades encargadas que sería cirugía de cabeza y cuello pero tras curso clínico agresivo, con múltiples factores de mal pronóstico y escasa respuesta al tratamiento,que ocasionó el desenlace fatal de la paciente.

\section{DISCUSIÓN:}

El caso presentado anteriormente nos describe un cuadro clínico poco frecuente en nuestra región y típico de un paciente con Linfoma extranodal de NK en el que existente algunos puntos significativos. El linfoma extranodal de NK representa un retodiagnóstico que requiere un alto índice de sospecha clínica, ya que es fácil confundirlo con otras enfermedades, ${ }^{2}$ incluyendo neoplasias, procesos infecciosos primarios por hongos, bacterianos o parasitarios y enfermedades autoinmunes. Un claro ejemplo es la leishmanisis la cual fue el primerdiagnóstico del paciente y se sospechaba como un desencadenador del desarrollo del linfoma pero no existen información clínica relevante ni otros caso clínicos reportados, esta es una enfermedad que se puede confundir fácilmente con un linfoma como lo es en este caso. La mayoría de casos se evidencia en paciente de mayor de 40 años ${ }^{3}$ y en nuestro caso es un paciente joven, por locual siempre es de importancia que ante cualquier sospecha clínica de este tipo de patología se puede realizar un correcto diagnóstico y en busca de tratamiento 
aunque se describió que dicha patología tienemal pronóstico y es de difícil manejo, pero setrata de buscar las mejores oportunidades y mejores condiciones para los pacientes. Dichoesto, es necesario enfocarnos siempre en la importancia de ver el paciente como un todo para así evaluar las opciones que se nos presenten y realizar un adecuado manejo médico.

En el caso específico de este paciente su mayor inconveniente que toma granimportancia fue la demora de autorizaciones y problemas administrativos por parte de su entidad prestado de servicio, cabe resaltarque esto es un problema común en nuestro país, y si ello, se hubiese solucionado oportunamente se hubiese podido cambiar eldesenlace de este.

\section{CONCLUSIONES:}

Patologías diversas y con variante presentación clínica son la causa de difícil manejo de la misma, así como su tratamiento el cual aun sigue siendo un reto para patologías como estas, Es importante conocerantecedentes, procedencia y toda clase dedato proporcionado por el paciente para su historial clínico. Por último, es indiscutible el mal enfoque desde el inicio de este paciente lo que nos enseña solo la relevancia de un adecuado enfoque de los pacientes. 


\section{REFERENCIAS:}

1- Nccn Clinical Practiceguidelines In Oncology

2- http://scielo.sld.cu/scielo.php?script=sci_arttext\&pid=S1029-30432017000300014

3- https://scielo.conicyt.cl/pdf/orl/v77n2/art14.pdf 